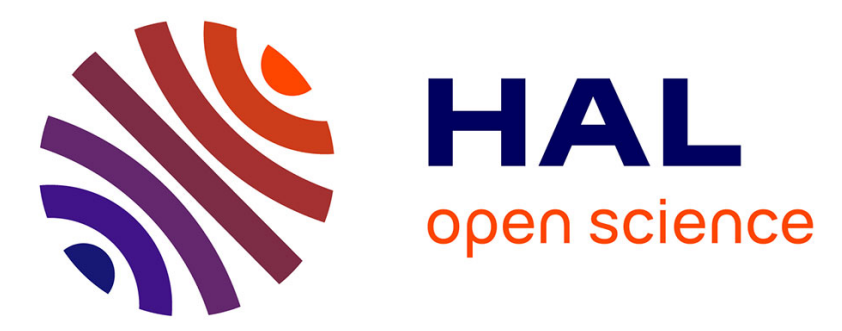

\title{
Circulation in a stratified and wind-forced Gulf of Lions, NW Mediterranean Sea: in situ and modeling data
}

\author{
Anne Petrenko, Yann Leredde, Patrick Marsaleix
}

\section{To cite this version:}

Anne Petrenko, Yann Leredde, Patrick Marsaleix. Circulation in a stratified and wind-forced Gulf of Lions, NW Mediterranean Sea: in situ and modeling data. Continental Shelf Research, 2005, 25 (1), pp.7-27. 10.1016/j.csr.2004.09.004 . hal-02110245

\section{HAL Id: hal-02110245 \\ https://hal.science/hal-02110245}

Submitted on 9 Aug 2021

HAL is a multi-disciplinary open access archive for the deposit and dissemination of scientific research documents, whether they are published or not. The documents may come from teaching and research institutions in France or abroad, or from public or private research centers.
L'archive ouverte pluridisciplinaire HAL, est destinée au dépôt et à la diffusion de documents scientifiques de niveau recherche, publiés ou non, émanant des établissements d'enseignement et de recherche français ou étrangers, des laboratoires publics ou privés. 


\title{
Circulation in a stratified and wind-forced Gulf of Lions, NW Mediterranean Sea: in situ and modeling data
}

\author{
Anne Petrenko ${ }^{\mathrm{a}, *}$, Yann Leredde ${ }^{\mathrm{a}}$, Patrick Marsaleix ${ }^{\mathrm{b}}$

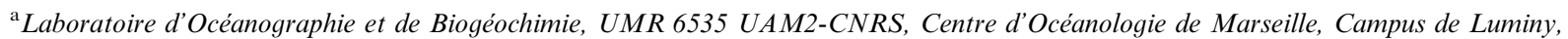 \\ case 901, Marseille cedex 09 13288, France \\ b Laboratoire d'Aérologie, UMR 5560 UPS-CNRS, Pôle d'Océanographie Côtiére 14, Avenue Edouard Belin, 31400 Toulouse, France
}

\begin{abstract}
ADCP, thermosalinograph, and meteorological data were collected during a short cruise (SARHYGOL 3; June 13-15, 2000) throughout the Gulf of Lions, NW Mediterranean Sea. The 3-D hydrodynamical model Symphonie reproduces well the circulation features observed in situ. The Northern Current (NC) - geostrophic current bordering the gulf along its continental slope - is well modeled with slight differences in its position. W henthe modeled stratification of the gulf is shallower than the measured stratification, the modeled NC is further offshore than the real NC (and reciprocally). The model allows the determination of the life-time and generating processes of the intrusions of the NC on the shelf. During the cruise, two different types of intrusions of the NC are found: (1) an intrusion at the eastern side of the gulf, that lasted 5 days and was due to a combination of the water column stratification and wind-forcing effects at the start of the continental shelf; (2) an intrusion at the center of the gulf, that lasted less than $12 \mathrm{~h}$ and was generated by the proximity of a positive and a negative wind stress curls. The coupled in situ data/model analysis also provides a better understanding on inertial oscillations. A strong inertial oscillation, with maximum amplitude of $60 \mathrm{~cm} / \mathrm{s}$, is clearly observed at the western side of the gulf due to the absence of the $\mathrm{NC}$ there. The model also exhibits this oscillation, and provides its temporal variations. The analysis, closely coupling in situ measurements and model results, provides information that would not have been obtained using either data separately.
\end{abstract}

Keywords: Current data; Modeling; Shelf edge dynamics; Inertial currents

\footnotetext{
*Corresponding author. Tel.: +33491829061; fax: +33491821991 .

E-mail address: petrenko@com.univ-mrs.fr (A. Petrenko).
}

\section{Introduction}

The Gulf of Lions (GoL) is located in the northwestern Mediterranean Sea. The main hydrodynamic features of this continental shelf have been previously described (Millot, 1999). The 
dominant forcings in the area are the strong northwestern (tramontane) and northern (mistral) winds, the western Mediterranean mesoscale circulation, and the fresh water input (Rhone River).

The winds generate classical oceanographic features, such as upwellings along straight coasts (Millot, 1982), and downwellings. The winds can both become very strong or die quite suddenly; and hence generate transitional circulation features, such as inertial oscillations (Millot and Crepon, 1981; Petrenko, 2003). These inertial oscillations can occur all year round, but they seem to be favored in stratified conditions. These transitional motions are classically filtered out of time series data (e.g., by applying a $40 \mathrm{~h}$ Lanczos filter) but they are more difficult to isolate in data sets acquired aboard a moving research vessel (RV).

The continental slope constitutes a long open boundary to the southeast of the gulf. Along this boundary, the main mesoscale circulation feature is a strong geostrophic current, the Northern Current (NC) (Millot, 1991). The shelf circulation is bounded and influenced by this current, which generally flows along the GoL continental slope from the Ligurian Sea to the Catalan Sea. It may also sometimes intrude on the continental shelf, especially at the eastern edge of the gulf (Millot and Wald, 1980; Petrenko, 2003). In this paper, an intrusion refers to any portion of the $\mathrm{NC}$ crossing the $200 \mathrm{~m}$ isobath and flowing over the continental shelf.

Fresh water inputs in the gulf vary throughout the year, with peaks during the rainy seasons generally in spring and fall (Moutin et al., 1998). The main input is the Rhone River plume. Its direction and extent are greatly affected by the wind (Demarq and Wald, 1984; Estournel et al., 2001; Marsaleix et al., 1998; Naudin et al., 2001). The plume sometimes extends all the way to the Spanish coast (Castellon et al., 1985).

Experimental studies have been done in the 1990s in the region, especially on: the variation of the NC offshore of Marseilles (Conan and Millot, 1995), localized current studies (Flexas et al., 2002), sediment transport in canyons (Monaco et al., 1990) or at the shelf break (Durrieu de Madron et al., 1999; Lapouyade and Durrieu de Madron,
2001), biogeochemical cycles in the gulf (Raimbault and Durrieu de Madron, 2003; and included literature), and the Rhone River plume (Naudin et al., 2001, and included literature). But the primary study goal of most of these works was not the entire shelf circulation, even if the latter obviously influences any other processes. Hence the SARHYGOL cruises were proposed in 2000-2001 to study the shelf circulation, in a quasi-synoptic way. Details of the strategy of these cruises are given in the Methods section. Previous modeling works in the region have generally corresponded to the processes studied and listed above. Concerning the $3 \mathrm{D}$ circulation modeling of the entire gulf and its boundary, the main and most recent works have been done with the OPA model (Delleville, 1997; Echevin et al., 2003), the Symphonie model (Auclair et al., 2003; Estournel et al., 2003) or the POM model (Echevin et al., 2000). The Symphonie model was chosen for this study because of its previous applications in the GoL. Indeed Estournel et al. (2003) showed that the shelf circulation and the $\mathrm{NC}$ observed during the FETCH experiment were quite well reproduced by this model. Recently, Symphonie was also successfully tested on the Rhone river plume circulation (Reffray et al., 2004) and on the dense water cascading over the continental shelf of the gulf (Dufau-Julliand et al., in press). In these last two studies, the model results were validated with in situ measurements. The important questions still inherent in these modeling studies are whether or not the main physical processes taking place in situ are well reproduced by the model; and, if yes, if the model can then increase our understanding of their generating physical processes.

The main objectives of the paper are to test whether the hydrodynamic features observed quasi-synoptically throughout the whole GoL can be reproduced by the Symphonie model, and, if yes, to use the model to better understand the generating processes of the observed currents. Both the Method section (Section 2) and the Results section (Section 3) presents first the data and second the model, or its outputs. Intrusions of the $\mathrm{NC}$ in the GoL and inertial oscillations are detailed in the Discussion section (Section 4). In 
the final section, the main results are summarized, and some perspective work briefly described.

\section{Methods}

\subsection{The Sarhygol cruises}

A series of seasonal short cruises (SARHYGOL: Regular and Automatic Survey of HYdrodynamics in the GoL) were initiated in 2000 to survey hydrodynamics features across the Gulf of Lions, northwestern Mediterranean Sea. Ten SARHYGOL cruises were done over the two-year period: 2000-2001. They were scheduled approximately every two months to sample the gulf circulation under different weather and stratification conditions. The SARHYGOL 3 cruise took place during June 13-15, 2000, leaving from and returning to Marseilles, France (Fig. 1). In order to get a quasi-synoptic view of the circulation, the RV Téthys II covered the entire gulf as quickly as possible with, as an upper speed limit, the speed

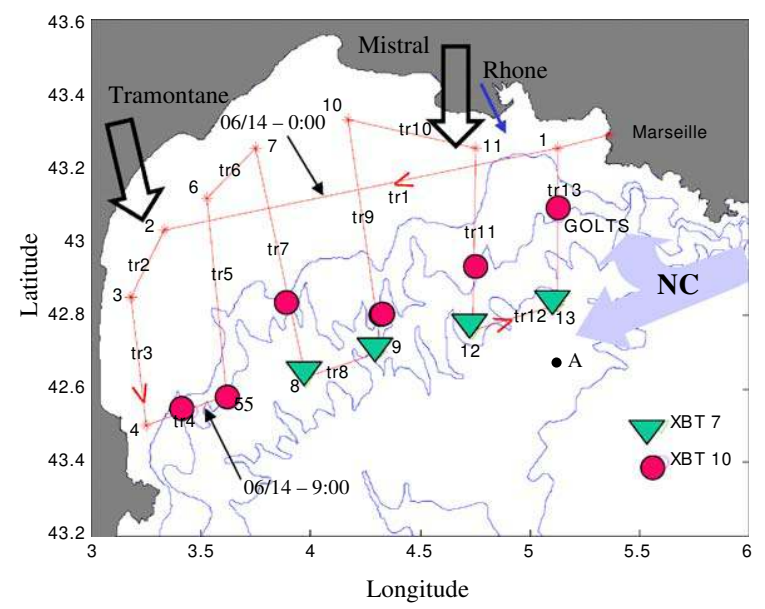

Fig. 1. Map of the Gulf of Lions. The track of the SARHYGOL cruise was done in the order indicated by the arrows. Changes of directions are incremented from 1 to 13 , and the corresponding transects labeled along the way. XBT 7 $(760 \mathrm{~m})$ locations are indicated by triangles, and XBT 10 $(200 \mathrm{~m})$ by circles. Isobaths at $100,200,1000$, and $2000 \mathrm{~m}$ are drawn. Principal forcings (winds: Mistral, Tramontane; Rhone River; Northern Current with potential intrusion) are represented by arrows. Station A of MOOGLI 2 is indicated. above which data acquisition quality would be altered ( 8 knots). With these conditions, the entire gulf was covered quickly (in about $48 \mathrm{~h}$ ) but it was not possible to stop the vessel to perform CTD stations. To obtain temperature profiles without stopping the RV, Sippican Expandable Bathy Thermographs (XBTs) were used (Table 1). Otherwise, throughout the cruise, continuous measurements were made with a RD Instruments hull-mounted ADCP, a Seabird thermosalinograph connected to a pumping system and a Batos meteorological station.

The ADCP is a broadband VMBB $150 \mathrm{kHz}$. The configuration used during all cruises is identical: 60 cells, $4 \mathrm{~m}$ depth bins, an ensemble average of $1 \mathrm{~min}$, and bottom tracking when possible. ADCP data analysis was done by the French INSU (Institut National des Sciences de $1^{\prime}$ Univers; http://www.insu.cnrs-dir.fr/). Precision on the ADCP data is better than $0.02 \mathrm{~m} \mathrm{~s}^{-1}$. No time or distance averaging has been done on the ADCP data. Current fluxes are calculated through surfaces orthogonal to the current main flow and given in Sv (1 Sverdrup $\left.=10^{6} \mathrm{~m}^{3} \mathrm{~s}^{-1}\right)$; details are given in Petrenko (2003).

Thermosalinograph data were analyzed with the Seasoft software (http://www.seabird.com/software/Seasoft.htm). Data were not filtered with Seasoft filter but erroneous peaks in the data were retrieved with matlab routines. XBT temperature profiles were collected along the $200 \mathrm{~m}$ isobath (XBT 10, profiling down to $200 \mathrm{~m}$ ) and at the offshore knots (XBT 7, profiling down to $760 \mathrm{~m}$ ) of the cruise tracks (Fig. 1). These measurements were calibrated with a Sippican calibration canister. Erroneous surface data due to air-water temperature gradients were corrected.

Wind was measured every $15 \mathrm{~s}$ by the meteorological station Batos, on board the ship. These data were averaged every $10 \mathrm{~min}$; and then interpolated every $1 \mathrm{~min}$ to correspond to the ADCP resolution. Since the winds vary on time scales smaller than the cruise period, the quasisynopticity hypothesis cannot reasonably be applied to the winds. Moreover, both for analysis and modeling, the meteorological conditions need to be known before the cruise (not only during the cruise) and throughout the GoL (not only on the 
Table 1

Data on specific locations along the trajectory of SARHYGOL 3

\begin{tabular}{|c|c|c|c|c|c|c|}
\hline & Longitude & Latitude & Date & Time & XBT type & Thermo. depth \\
\hline Marseille & 5.36 & 43.29 & $6 / 13 / 00$ & 4:42 PM & - & - \\
\hline Station 1 & 5.13 & 43.25 & $6 / 13 / 00$ & 5:47 PM & - & - \\
\hline Station 2 & 3.33 & 43.03 & $6 / 14 / 00$ & 3:29 AM & - & - \\
\hline Station 3 & 3.18 & 42.85 & $6 / 14 / 00$ & 4:55 AM & - & - \\
\hline Station 4 & 3.25 & 42.5 & $6 / 14 / 00$ & 7:28 AM & - & - \\
\hline $4 / 5$ & 3.45 & 42.54 & $6 / 14 / 00$ & 8:30 AM & XBT 10 & No \\
\hline Station 5 & 3.62 & 42.58 & $6 / 14 / 00$ & $9: 30 \mathrm{AM}$ & XBT 10 & 65 \\
\hline Station 6 & 3.53 & 43.12 & $6 / 14 / 00$ & 1:25 PM & - & - \\
\hline Station 7 & 3.75 & 43.25 & $6 / 14 / 00$ & 2:58 PM & - & - \\
\hline $7 / 8$ & 3.90 & 42.83 & $6 / 14 / 00$ & 6:00 PM & XBT 10 & $15-35$ \\
\hline Station 8 & 3.98 & 42.63 & $6 / 14 / 00$ & 7:29 PM & XBT 7 & 40 \\
\hline Station 9 & 4.32 & 42.70 & $6 / 14 / 00$ & 9:36 PM & XBT 7 & $9-11$ \\
\hline $9 / 10$ & 4.29 & 42.80 & $6 / 15 / 00$ & 10:23 PM & XBT 10 & $7-17$ \\
\hline Station 10 & 4.17 & 43.33 & $6 / 15 / 00$ & 2:20 AM & - & - \\
\hline Station 11 & 4.75 & 43.25 & $6 / 15 / 00$ & 5:33 AM & - & - \\
\hline $11 / 12$ & 4.74 & 42.95 & $6 / 15 / 00$ & 7:37 AM & XBT 10 & $7-19$ \\
\hline Station 12 & 4.74 & 42.76 & $6 / 15 / 00$ & 9:02 AM & XBT 7 & 12 \\
\hline Station 13 & 5.13 & 42.83 & $6 / 15 / 00$ & $11: 22 \mathrm{AM}$ & XBT 7 & 8 \\
\hline GOLTS & 5.13 & 43.07 & $6 / 15 / 00$ & 1:08 PM & XBT 10 & 14 \\
\hline Station 1 & 5.13 & 43.25 & $6 / 15 / 00$ & 2:25 PM & - & - \\
\hline Marseille & 5.36 & 43.29 & $6 / 15 / 00$ & 3:38 PM & - & - \\
\hline Station A & 5.13 & 42.66 & & & & 10 \\
\hline Tinit & & & & & & 8 \\
\hline$T$ simul & & & & & & 18 \\
\hline
\end{tabular}

Longitude (degree East), latitude (degree North), date, time, type of XBT — when collected at that location —and corresponding depth of the top of the thermocline. Two depths indicate that the temperature profile exhibits two thermoclines. Relevant information are also provided for station A (MOOGLI 2) and for two modeled output profiles (Tinit and $T$ simul).

cruise track). Hence Aladin, a French weatherforecast model (Météo-France), was used to provide the necessary additional meteorological information. Winds modeled by Aladin are averaged over a 3 -h period, on a $0.1-0.1^{\circ}$ grid throughout the gulf. Excellent agreement was found between measured and modeled winds during MOOGLI 1 (Estournel et al., 2003).

\subsection{The Symphonie model}

The model used is basically the three-dimensional primitive equations model described in Estournel et al. (1997). The three components of the current, surface elevation, temperature and salinity are computed on a $\mathrm{C}$ grid. A generalized "terrain following" co-ordinate system is used. The turbulence closure is achieved through a prognostic equation for the turbulent kinetic energy and a diagnostic equation for the mixing and dissipation length scales (Gaspar et al., 1990). A leap frog scheme is used for the time stepping. Calculus costs are limited thanks to a time splitting technique that permits to compute the vertical shear of the current and its depth-averaged component separately with appropriate time steps.

Open boundary conditions are those used in Estournel et al. (2003), i.e. a radiation condition combined to restoring terms to the large scale thermohaline circulation. A $3 \mathrm{~km}$ horizontal grid mesh and 25 vertical levels were used.

The external forcings are of three types: river discharges, atmospheric fluxes and large scale inputs at lateral open boundaries. The "Companie Nationale du Rhône" graciously provided daily flux of the Grand Rhone measured at Beaucaire, the station closer $(56 \mathrm{~km})$ to the river outlet. The atmospheric forcings are provided by the 3-h 
averaged outputs of the weather-forecast model Aladin (Météo-France). The restoring terms of the open boundary scheme allow to force the model with the characteristics of the general circulation at the regional scale.

To initialize the model in a smooth way at the beginning of the cruise, and to weaken disturbances due to the spin up phase, efforts were made in two ways:

(1) a margin of 19 days before the cruise is used, leading to a 21-day simulation. This allows the establishment of circulation features that are longer than the duration of the campaign (e.g. thermohaline currents, Rhone river plume).

(2) a specific scheme of initialization was developed to start the simulation with the seasonal mean features of the NC. As the bathymetry of the Gulf of Lions is characterized by a wide continental shelf bordered by a steep shelf break indented by numerous and deep canyons, the initial field has to be adjusted to the bathymetry in order to be stationary (Auclair et al., 2000a). If not adjusted, simulations can start with a long and unstable spin up; at the end of which, the mean characteristics of the initial state can be lost. The method used to get the adjustment of the initial state (Fig. 2) to the bathymetry is described in Estournel et al. (2003). The main steps of the method are presented in the appendix.

One interest of this method is to make some key hypothesis on the $3 \mathrm{D}$ structure of the large scale forcing current. Briefly, the parameters that can be adjusted, are:

(a) the vertical profiles $R(z)$ representing the vertical shear of the geostrophic current,

(b) the strength of the current at open boundaries via the parameter $R^{*}$ (see appendix).

(c) the vertical reference profile of salinity and temperature, and so density.

For the vertical shear, $R(z)$, an e-folding type function-concentrating the geostrophic current within a 300-m thick surface layer - was chosen. The strength of the current at the upstream

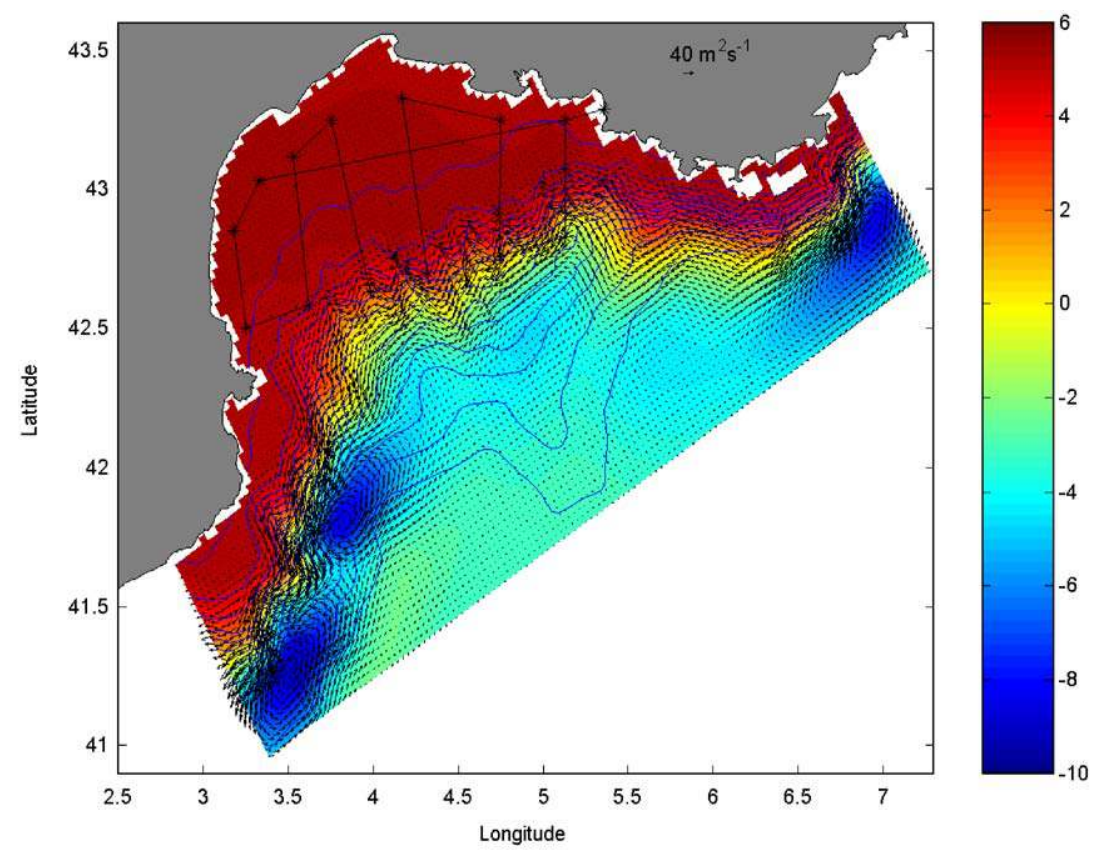

Fig. 2. Symphonie initial state (May 25) of transport (arrows; $\mathrm{m}^{2} \mathrm{~s}^{-1}$ ) and free surface elevation (colors; $\mathrm{cm}$ ). Model bathymetry is represented by contours every $200 \mathrm{~m}$. 
boundary condition is set to $1.8 \mathrm{~Sv}$. The hydrographic (T, $\mathrm{S}$ and $\rho$ ) data are given by the in situ measurements. The profile at station 13, located in the NC (Fig. 1), is used as the temperature reference profile. The salinity profile is the one of the station A of the Moogli 2 cruise (see explanations in Section 3.2).

\section{Results}

The following sections are all composed similarly: first, in situ data are presented; second, the corresponding model inputs or outputs; third, a comparison is made between the first two results.

\subsection{Winds}

Winds measured on the RV during the cruise varied both in space and time (Fig. 3a). A northwest tramontane was blowing on the western side of the GoL. The mistral coming from the north blew south of the Rhone valley on June 15 (transects 10, 11, 12; Fig. 3a). Maximum wind intensity was about $10 \mathrm{~m} \mathrm{~s}^{-1}$. The occurrence of both (tramontane and mistral) winds is very frequent in the GoL. This is a reason why we focus more particularly on this campaign.

In order to simulate currents resembling the measured ones, it is necessary to know the winds, as accurately as possible and with a high resolution, for the entire studied zone. Aladin outputs were generally consistent with the winds measured (Fig. 3a). During the cruise, in order to compare the wind data measured on board with the simulated wind, the latter is interpolated both spatially and temporally in order to be represented along the ship track (Fig. 3b). The winds, in particular the tramontane, are consistent until 9:30 on June 14, which corresponds to the end of transect 4. Afterwards, while the RV meteorological station measures a steady tramontane (transects 5, 6, 7, 8, and 9) until June 15, 2:20, the Aladin model shows no corresponding wind. Then, the measured and model winds agree again: the mistral blows on transect 10 , and weakens on transects 11 and 12. The differences indicated

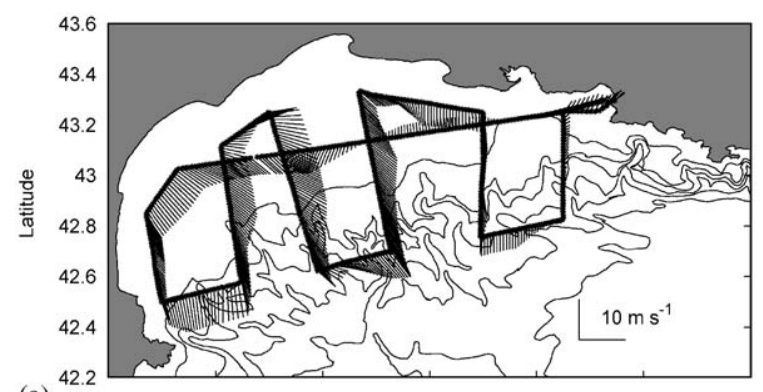

(a)

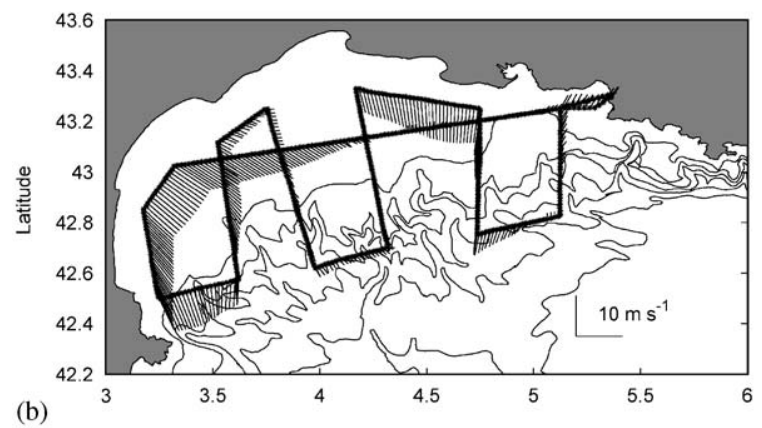

Fig. 3. Winds $\left(\mathrm{m} \mathrm{s}^{-1}\right)$ (a) measured by the meteorological station on the Tethys II (represented every $5 \mathrm{~min}$ ) during the SARHYGOL 3 cruise; (b) modeled by ALADIN interpolated along the cruise track. Model bathymetry is represented by contours every $200 \mathrm{~m}$.

above will have to be taken into account in the interpretation of the Symphonie model results.

Aladin model also provided data more extended, both in space and time, than the wind measured on board the Tethys. Before the cruise, the tramontane blew strongly (Aladin wind stress $=0.9 \mathrm{~Pa}$; corresponding to a wind about $20 \mathrm{~m} \mathrm{~s}^{-1}$ ) on June 12, the day before the beginning of the cruise. The mistral, channeled south of the Rhone valley, was not as strong (Aladin wind stress = $0.5 \mathrm{~Pa}$ ) as the tramontane. The winds weakened on June 13. At the beginning of the cruise, the tramontane blew on the western side of the GoL, close to the coast (e.g., winds on June 14; Fig. 4). At this time, the RV was on the first transect and not yet in the windy zone. This example proves that - as expected - the winds are not homogeneous throughout the gulf, and confirms that the wind measurements made on the boat are not sufficient to force the model. 


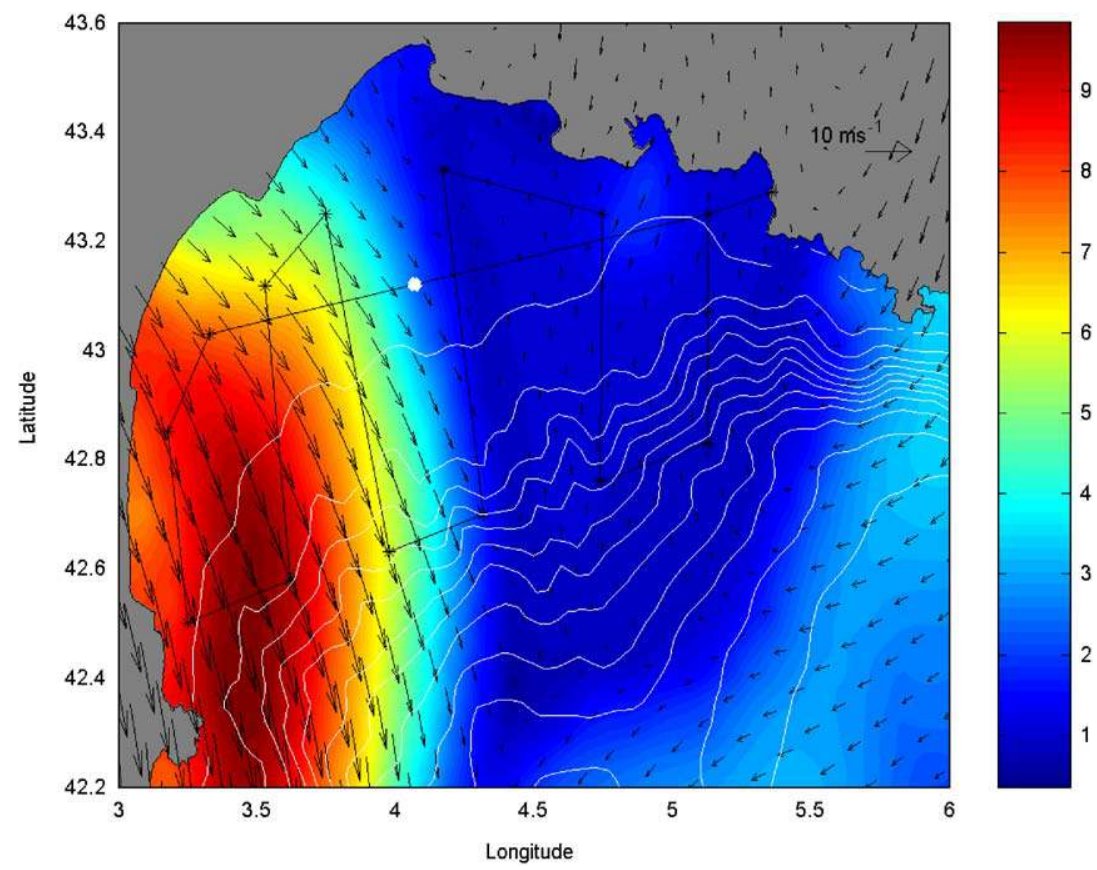

Fig. 4. Wind (arrows and colors; $\mathrm{m} \mathrm{s}^{-1}$ ) throughout the Gulf of Lions, modeled by ALADIN at $00 \mathrm{~h} 00$ on June 14. The boat position is indicated by the white circle. Model bathymetry is represented by contours every $200 \mathrm{~m}$.

\subsection{Vertical stratification}

Temperature profiles measured with XBTs can be separated in four different types: (a) no thermocline (station 4/5), (b) one deep thermocline (station 5), (c) two thermoclines: a shallow one and a deep one (stations $7 / 8$ and 8 ), (d) one or two shallow thermoclines (stations 9, 9/10, 11/12, 12, 13, 14) (Table 1). A thermocline is classified as "shallow" when the top of its temperature gradient is shallower than $20 \mathrm{~m}$, and as "deep" when it is deeper than $35 \mathrm{~m}$. The shallow thermoclines correspond to diurnal thermoclines. The deep thermoclines could be seasonal thermoclines. But, at station 5, the mixed layer is $65 \mathrm{~m}$ thick. The top of the seasonal thermocline is not expected to be located as deep as $65 \mathrm{~m}$ in June in the GoL. Here, this deep thermocline, measured on June 14, is due to a big storm event (June 10-13, with very strong winds lasting from June 11 to midday on June 12; Fig. 12). The GoL can be separated in two zones: the western side with a deep or no thermocline (cases a, b and c); the eastern side with shallow diurnal thermoclines (case d). To compare with model profiles, the term "main" thermocline will be used referring to the deepest (whether shallow or deep) thermocline measured, when it exists.

No profile of salinity was acquired during the cruise. Since density profiles are needed as initial and boundary conditions for the model, CTD data collected during a cruise in June 98 (MOOGLI 2) were used (Raimbault and Durrieu de Madron, 2003). The CTD data from MOOGLI 2, which temperature profile (station A) agreed best with our XBT data (station 13, Fig. 5), were used to provide salinity, and hence density profiles to the model.

The profiles of MOOGLI 2 station A (both temperature and salinity) are used as reference profiles to initialize the model (see appendix). The simulated, vertical stratification agrees with the few measured temperature profiles. The initial profile (Fig. 5, Tinit) behaves like the XBT 13 


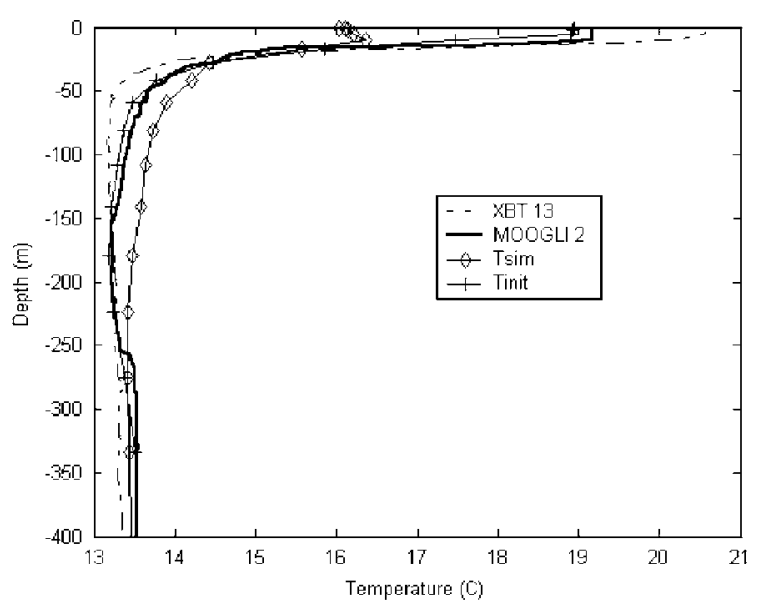

Fig. 5. Temperature profiles measured at location 13 (XBT13), and at station A during MOOGLI 2. Initial temperature profile on May 25 (Tinit) and simulated temperature profile on June 15 (Tsim) at location 13 .

profile, with a thermocline starting at $8 \mathrm{~m}$. The simulated profile obtained after 21 days of simulation (Fig. 5, Tsim) has changed quantitatively. The depth of its thermocline is $18 \mathrm{~m}$. A cooling (about $4{ }^{\circ} \mathrm{C}$ ) occurred near the free surface, due mainly to the wind gust of June 12. Below the thermocline, from 45 to $250 \mathrm{~m}$ depth, the simulated temperature is slightly warmer $\left(\sim 0.3{ }^{\circ} \mathrm{C}\right)$ than the observed one. This difference comes from the influence of the $\mathrm{NC}$ on the model vertical mixing. Indeed, the $\mathrm{NC}$ extends from the surface down to $250 \mathrm{~m}$ (see Section 3.3). Throughout this current, the turbulent kinetic energy produced by vertical shear stress is important. Despite the pycnocline stabilizing effect and its buoyancy dissipation, the turbulent closure scheme (Gaspar et al., 1990) lets temperature (and other tracers) slightly diffuse through, warming the water column below the thermocline. This explains the slightly warmer temperature of the modeled NC.

Throughout the simulation domain, the main thermocline remains horizontally quite uniform. The top of the temperature gradient is constantly around $15-20 \mathrm{~m}$, and its lower boundary is around $40-45 \mathrm{~m}$. The modeled thermocline is hence generally shallower (deeper) than the measured thermocline on the eastern (western) side of the gulf (see XBT data; Table 1). The main consequence of these differences will be stressed in the following section.

Additionally, the spatio-temporal analysis of the modeled temperature shows a variability due to the NC or to other physical phenomena (e.g., the Rhone river plume or the coastal upwellings). Moreover, the realistic thermal fluxes of the ocean-atmosphere interface allows the model to reproduce well thermoclines, and their eventual oscillations. Indeed the thermocline can oscillate due to land-sea breezes (day-night frequency), or due to strong wind bursts (inertial frequency, see Section 3.5). XBT data are too scarce to allow a comparison with these model results. So, as no real validation is feasible, these model results are not detailed any further.

\subsection{The Northern Current (NC)}

The SARHYGOL cruises were not dedicated to the NC observation, but rather to the shelf circulation. Hence not all the north-south transects cut the NC through its entire cross section. Only transect 13 (the most eastern north-south transect, see Fig. 1) crosses the NC entirely. Indeed, this transect extends south further than the $1000 \mathrm{~m}$ isobath. Since the NC is located between the 200 and $1000 \mathrm{~m}$ isobaths, transect 13 provides a complete section of the NC (Fig. 6a and b).

Along transect 13, the NC is $200 \mathrm{~m}$ deep and $16 \mathrm{~km}$ wide. Its maximum speed is about $0.6 \mathrm{~m} \mathrm{~s}^{-1}$, and its mean speed $\sim 0.2 \mathrm{~m} \mathrm{~s}^{-1}$. It is going roughly westward (core direction: $265^{\circ}$ ), with a flux of $0.8 \mathrm{~Sv}$. These characteristics are comparable with the ones found in June 98 (Petrenko, 2003).

A first evaluation of the model results consists in comparing measured and modeled velocities by interpolating the simulated velocities along transect 13 at each spatio-temporal position of the measured ADCP (Fig. 6c and d). The comparison of observed and modeled data (Fig. 6) shows that the NC is qualitatively well simulated. Quantitatively, the simulated $\mathrm{NC}$ is wider $(28 \mathrm{~km})$ and deeper $(250 \mathrm{~m})$ than the measured one, with a maximum velocity slightly weaker $\left(0.55 \mathrm{~m} \mathrm{~s}^{-1}\right)$. This results in a simulated flux of $\sim 1.2,0.4 \mathrm{~Sv}$ 


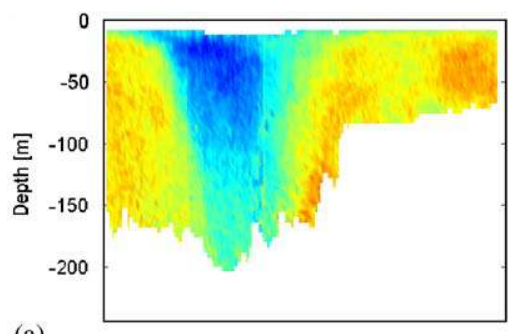

(a)

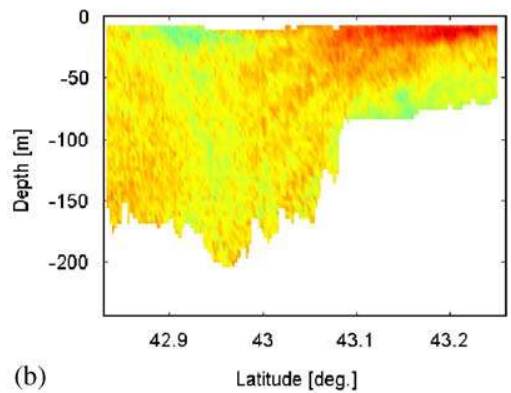

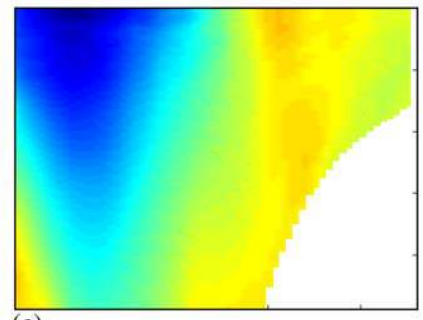

(c)

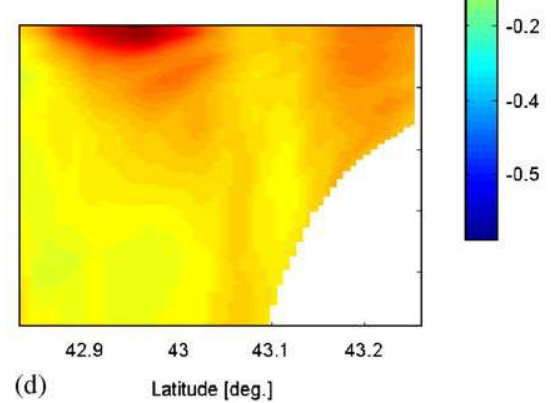

Fig. 6. Vertical sections (depth vs. latitude) of the horizontal currents (colors; $\mathrm{m} \mathrm{s}^{-1}$ ) along transect 13: (a) the observed west-east component (east, positive), (b) the observed south-north component (north, positive), (c) the simulated west-east component (east, positive), (d) the simulated south-north component (north, positive).

higher than the flux calculated with the ADCP measurements.

At this eastern end of the gulf, the core of the modeled NC is located a little more south (by less than 0.1 degree of latitude) than the measured NC. In the western side of the gulf, a quantitative comparison of the in situ and simulated $\mathrm{NC}$ is not possible since the $\mathrm{NC}$ is not detected by the ship ADCP along transects 4 and 5 (Fig. 7). In that region, the simulated $\mathrm{NC}$ is located more to the north than its real counterpart and is visible on those transects. Hence, when the modeled stratification of the gulf is shallower than the measured stratification (see Section 3.2), the modeled NC is further offshore than the real NC (and reciprocally).

It was not the main goal of the SARHYGOL cruises to observe and understand the NW Mediterranean general circulation. But this circulation is the lower border of the GoL shelf circulation. The former can completely condition the latter, notably by intruding on the shelf (see Section 3.4 Shelf circulation), or by overlapping the shelf wind-driven circulation (see Section 3.5 Inertial oscillations).

\subsection{Shelf circulation}

As shown in previous studies (Conan and Millot, 1995; Estournel et al., 2003; Flexas et al., 2002; Millot, 1982; Millot, 1990; Millot and Crepon, 1981; Petrenko, 2003), the shelf circulation is mainly driven by the weather conditions and the vertical stratification. The shelf circulation is generally westward (Fig. 7a and b) with several striking features that will be discussed afterwards. Two depths (24 and $80 \mathrm{~m}$ ) have been chosen for the figures of current horizontal sections since they generally represent well the upper and lower layers of the water column.

The simulated currents interpolated along the cruise track (Fig. 7c and d) can be compared to those measured (Fig. 7a and b), with all the precautions imposed by such an exercise. The data simulated at the beginning of the cruise (transects $1,2)$ are in very good agreement with the in situ data. At the beginning of transect 1, a strong current is detected toward the northwest, along the coast (Fig. 7a). The same current is measured $45 \mathrm{~h}$ later at the end of the transect 13. Along transect 1 , this strong current is then westward and is 

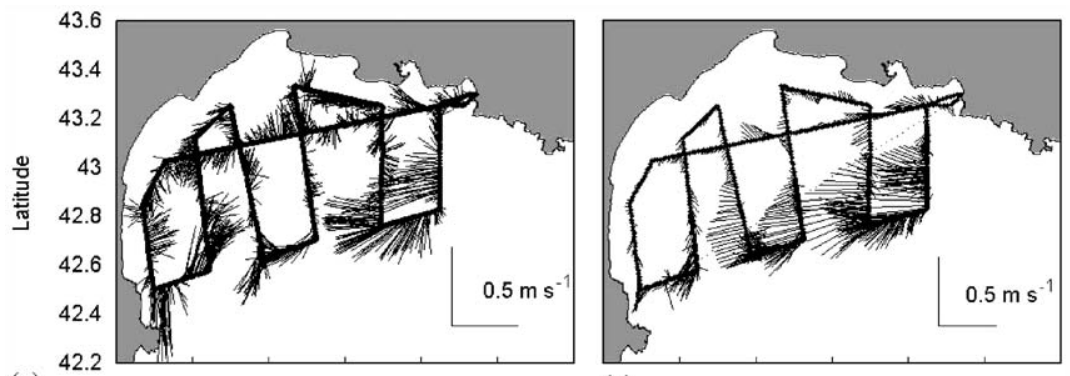

(a)

(c)
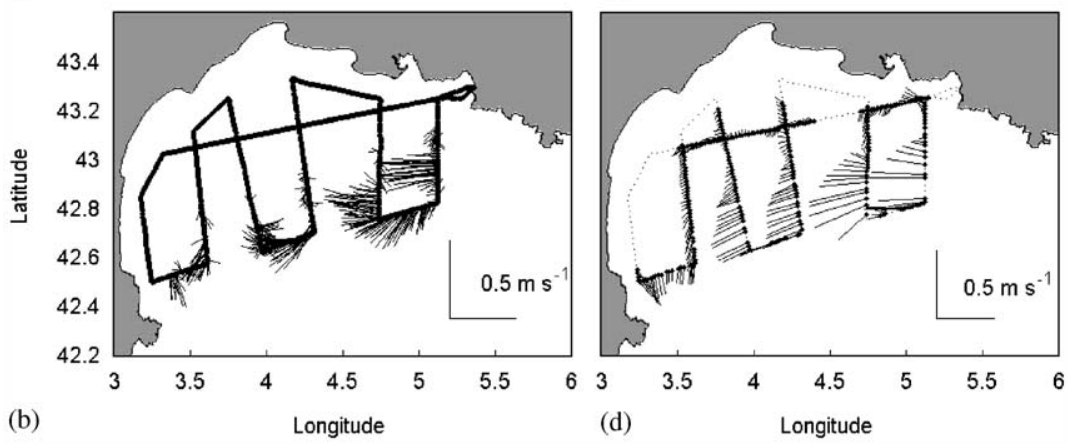

Fig. 7. Maps of the Gulf of Lions with horizontal currents: measured (a) at $24 \mathrm{~m}$, (b) at $80 \mathrm{~m}$; simulated and interpolated along the cruise track, (c) at $24 \mathrm{~m}$, (d) at $80 \mathrm{~m}$.

present over the northern part of the gulf, facing the Rhone region (Fig. 7). Then this coastal current goes southward, and is detected offshore Cap d'Agde.

East of the Rhone, the model reproduces well the strong northwest current (beginning of transect 1, Fig. 7c). West of the Rhone, the current is also present, but weaker than the measured one. The model helps us interpret these currents; this would not have been possible with only the in situ data. In fact this strong northwestward current is an intrusion of the $\mathrm{NC}$ on the eastern side of the GoL (Fig. 8). This secondary coastal branch of the NC originates offshore of Toulon (around longitude $5.5^{\circ} \mathrm{E}$ ), and is probably due to the combined effects of bathymetry and of particular weather and stratification conditions (see Discussion). It lasts 5 days in the model simulation; and, as mentioned above, is detected twice during the cruise, with a 45-h interval in between.

Further along transect 1 , currents are weak, with a good consistency between simulated and observed data. Then, still on transect 1, a strong $\left(0.3 \mathrm{~m} \mathrm{~s}^{-1}\right)$ northward current is detected around $4.0^{\circ} \mathrm{E}$ (between transects 7 and 9), at $00 \mathrm{~h} 00$ on June 14 (Fig. 7a). The model outputs show a current at the same place, with the same strength and direction (Figs. 7c and 8c). The model successive outputs prove that this northward current originates mainly from an intrusion of the $\mathrm{NC}$ on the continental shelf in the middle of the gulf (Figs. 7 and 8). The model also shows that this northward intrusion is reinforced by a shelf current coming from the Rhone region. Gathering the information from this subsection and the previous one, it seems that, at the beginning of the cruise (until early on June 14), the Rhone plume loops anticyclonically and joins the northward NC intrusion (Figs. 7 and 8). Later (June 14, 9h00), the northward NC intrusion has mainly disappeared (Fig. 8b). The anticyclonic Rhone loop is further to the west, with its western branch becoming a coastal current about Cap d'Adge, as detected in the data (Fig. 7) and discussed before. The model outputs, confirmed by the observations, have enabled us to demonstrate the presence of this intrusion. Moreover, the model shows that this intrusion is transitional since it lasts less than $12 \mathrm{~h}$. 


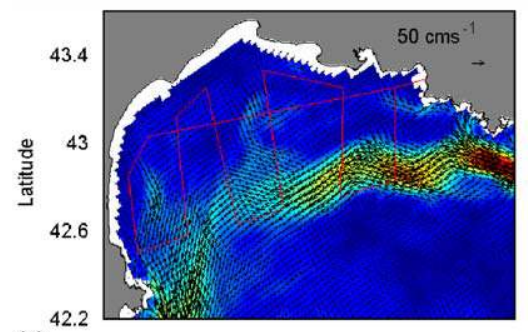

(a)
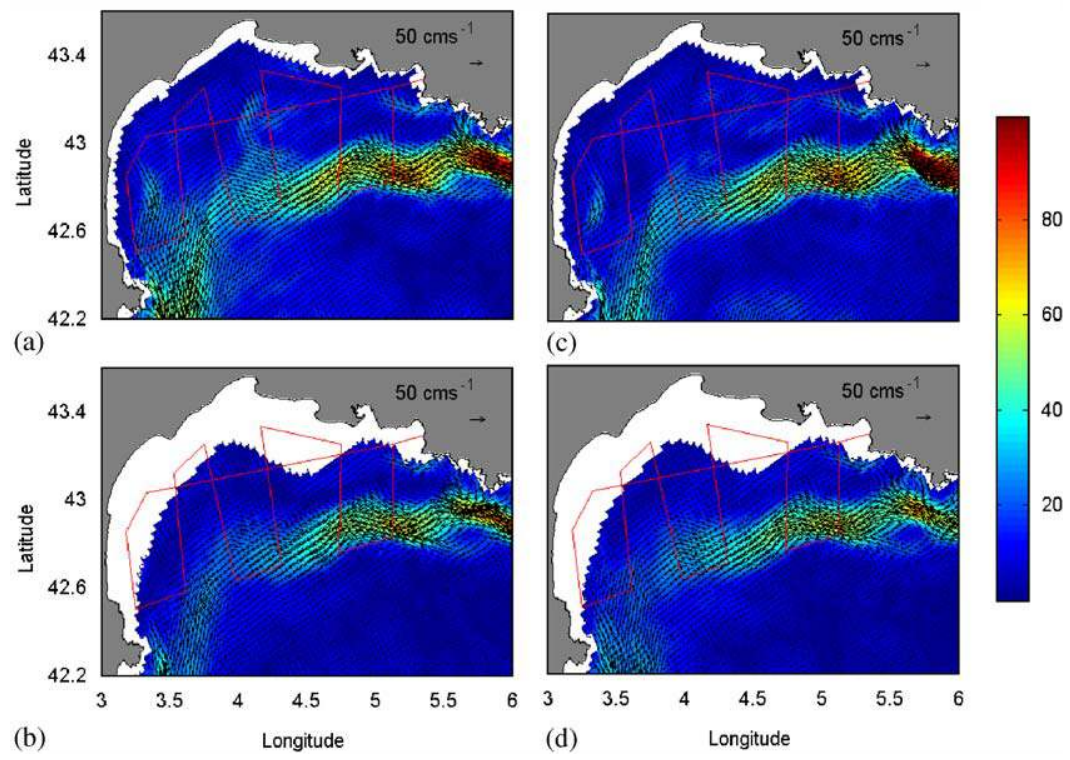

(c)

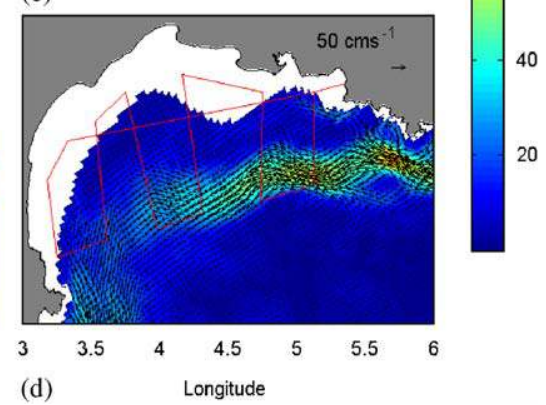

Fig. 8. Currents (colors; $\mathrm{m} \mathrm{s}^{-1}$ ) simulated on June 14, (a) $00 \mathrm{~h} 00$ at $24 \mathrm{~m}$, (b) $00 \mathrm{~h} 00$ at $80 \mathrm{~m}$, (c) $09 \mathrm{~h} 00$ at $24 \mathrm{~m}$, (d) $09 \mathrm{~h} 00$ at $80 \mathrm{~m}$.

An eastern current is detectable on transects 3 , 5, 7, 9, and 11 (Fig. 7a). It is about $60 \mathrm{~m}$ deep on the western side of the gulf (transects $3,5,7$ ). It extends down to $120 \mathrm{~m}$ between isobaths 100 and $200 \mathrm{~m}$, on transect 11 . On the western side of the GoL, this eastern current may be the southern loop of a cyclonic gyre. Indeed, before (during) the cruise, a strong (mild) tramontane was blowing. Under tramontane conditions, a cyclonic gyre was also observed during June 98 (Petrenko, 2003). The model also shows this eastern current but only on transects 3 and 5. It is weaker than the measured current on transect 3, and about the same strength on transect 5 . This eastern current is not detected on transects 7, 9 and 11 because the modeled $\mathrm{NC}$ is present at the corresponding latitudes.

In the most western part of the GoL, the model simulates well the coastal jet going southward. This jet is maintained by the tramontane and the effect of Cap Creus (Fig. 8). Such feature can be accompanied by a coastal downwelling. This downwelling is present in the model outputs (data not shown). In situ measurements were not done south of transect 4; so no validation of the downwelling could be made with the data. Other- wise, the closest observations show that the vertical structure of the horizontal currents is mode 1 barocline, with a strong vertical shear around $50-60 \mathrm{~m}$, which corresponds to the depth of the thermocline.

\subsection{Inertial oscillations}

On transect 4, a strong northeast current (maximum $0.6 \mathrm{~m} \mathrm{~s}^{-1}$ ) can easily be detected in the currents measured in the upper layer (Fig. 7a). It is rather peculiar at this location since one expects the $\mathrm{NC}$ to be present there. The vertical section of the currents show a strong shear between the surface currents going northeast and the deepest currents (below 60-70 m) going southwest (Figs. 7 and 9, a and b). This could correspond to the characteristic baroclinic structure of an inertial oscillation. At the end of transect 4 (station 5), the thermocline was measured at $65 \mathrm{~m}$ depth (Section 3.2). This agrees with the shear observed in the currents. Moreover, phase unwrapping of the current shear (Chereskin et al., 1989) confirms that a negative slope, approximately equal to $-f o$ (Coriolis factor), is present on the eastern section of transect 4 (data 
not shown). This confirms that an inertial oscillation is present there.

Taking into account the dominance of a northwest tramontane in the area, a surface inertial oscillation oriented northeast could originate from a wind intensity variation having occurred about modulo half the Coriolis period $(\sim 9 \mathrm{~h}$, since $T_{\text {fo }}=17.5 \mathrm{~h}$ ) before. The eastern side of transect 4 was done between 8:30 and 9:30 on June 14 (Table 1 and Fig. 3). Using data only acquired during the cruise, one would observe that, at about midnight between June 13 and 14, the RV enters into a zone where the tramontane is present (Fig. 3 ), and would conclude that this wind increase could have caused the inertial oscillation observed on transect 4.

The model currents appear quite different than the observed ones in that zone (Fig. 9). Nonetheless, inertial oscillations are also present and it will be shown that the model results provide better information, than in situ data, on the start and duration of this inertial oscillation.

As it was shown in the previous section, when the currents are relatively permanent, their ob- servation and analysis are possible with the chosen cruise strategy (e.g., transect 13; Fig. 6). But the analysis of the model outputs interpolated along transect 4 (Figs. 7 and 9, c and d) is difficult since, on this transect, some of the currents are transitional. Hence it is difficult to uncouple the temporal and spatial scales of the currents measured along the transect. Indeed, the horizontal axis (Fig. 9c and d) corresponds, for transect 4, to the range of longitude: $3.25-3.62^{\circ} \mathrm{E}$. But it also corresponds to the temporal range $7 \mathrm{~h} 28$ to $9 \mathrm{~h} 30$ (June 14). Luckily, time varies linearly with longitude (since the RV cruised at a constant speed). But, during these $2 \mathrm{~h}$, the inertial currents have the time to turn by nearly $45^{\circ}$. This is why it was chosen to represent the model outputs at a fixed point, rather than to follow the temporal evolution of the currents. Fig. 10 represents the eastward and northward velocities simulated at point $\mathrm{O}$ (latitude $42.5^{\circ} \mathrm{N}$, longitude $3.5^{\circ} \mathrm{E}$ ) between June 12, 00h00 and June 15, 18h00.

In order to filter the inertial components, even in a crude way, these simulated currents are averaged in time at every depth (Fig. 11). The mean

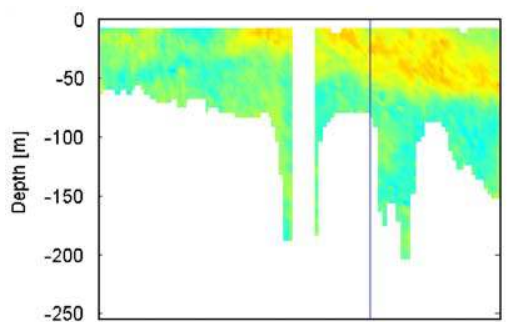

(a)

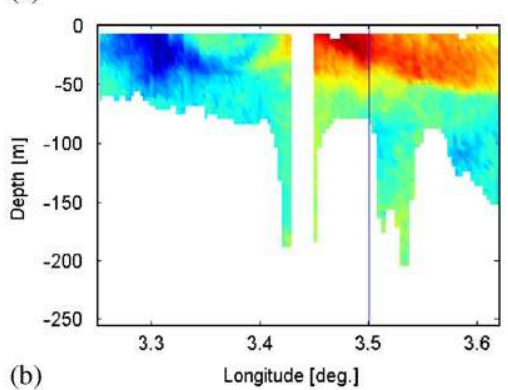

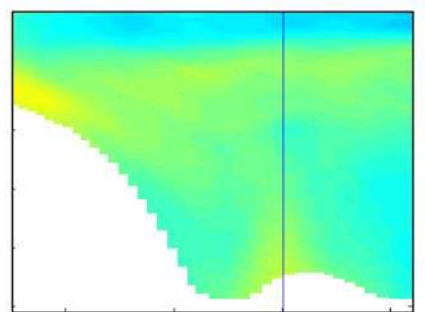

(c)
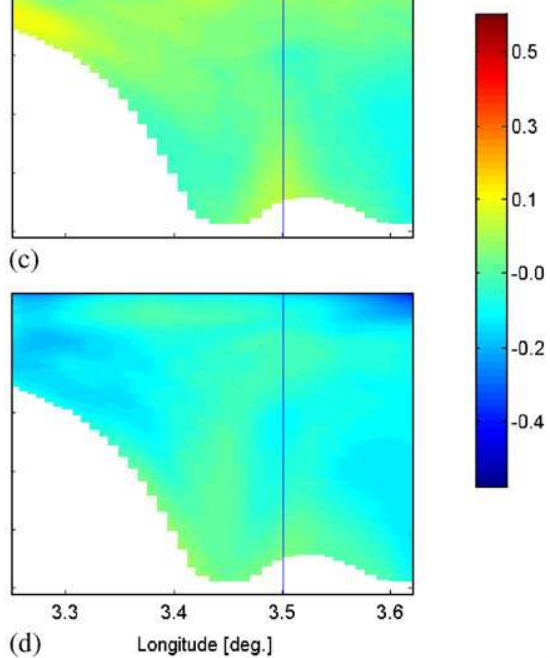

(d)

Fig. 9. Vertical sections (depth vs. latitude) of the horizontal currents (colors; $\mathrm{m} \mathrm{s}^{-1}$ ) along transect 4: (a) the observed west-east component (east, positive), (b) the observed south-north component (north, positive), (c) the simulated west-east component (east, positive), (d) the simulated south-north component (north, positive). The dotted line marks the O location (passed by the RV on June 14, 09h00, latitude 42.5, longitude 3.5). 


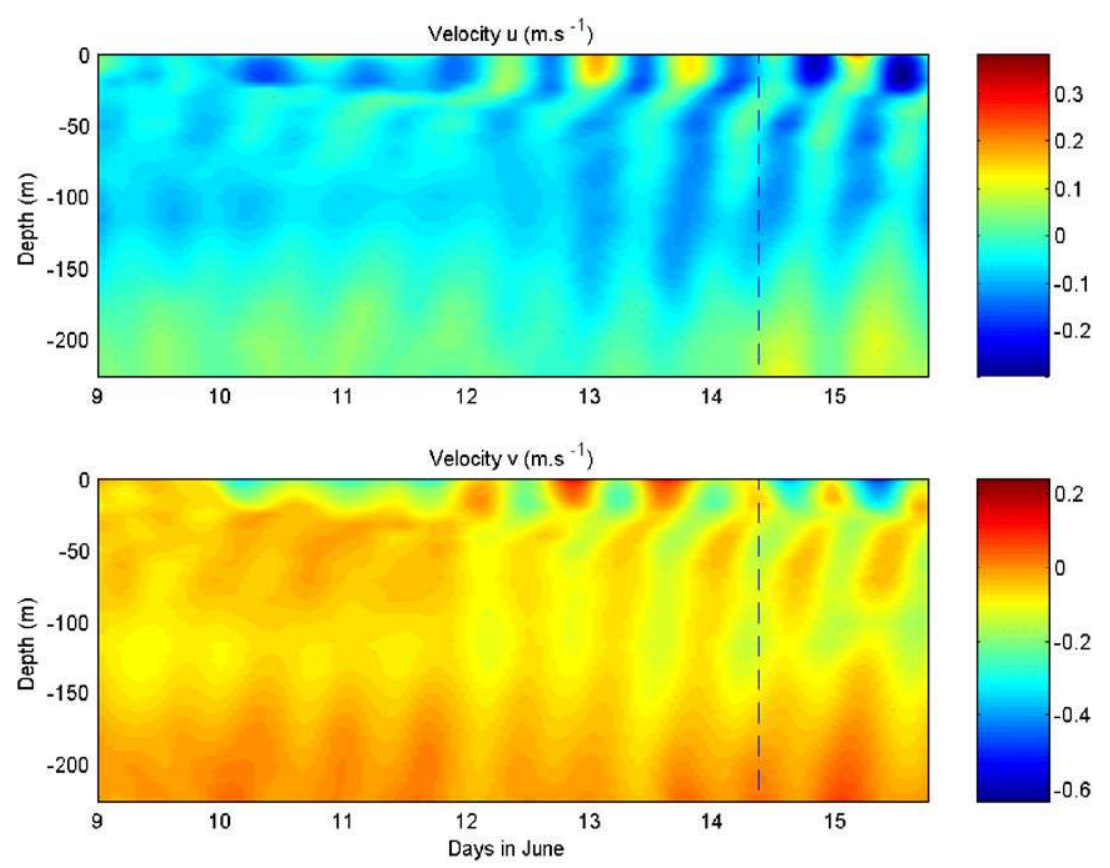

Fig. 10. Eastward (up) and northward (bottom) velocities $\left(\mathrm{m} \mathrm{s}^{-1}\right)$ simulated at the point $\mathrm{O}$ (latitude $42.5^{\circ} \mathrm{N}$, longitude $3.5^{\circ} \mathrm{E}$ ) between June 9, 00h00 and June 15, 18h00. The dotted line marks the time (June 14, 09h00) when the RV goes by O.

component, going towards the south-southwest, results from the geostrophic balance and represents the NC in this zone. As indicated in Section 3.3 , in that zone, the modeled $\mathrm{NC}$ is located further north than in the observations. The first layer, above the thermocline $(40 \mathrm{~m})$, is marked by a strong and sheared average current (up to $0.2 \mathrm{~m} \mathrm{~s}^{-1}$; Fig. 11). The current of the second layer, below the thermocline, has a uniform average current of $\sim 0.1 \mathrm{~m} \mathrm{~s}^{-1}$ down to $120 \mathrm{~m}$. Then, it decreases to be nearly null down at the bottom. Note that Fig. 11 is realized with the model outputs between June 9, 00h00 and June 15, $18 \mathrm{~h} 00$, but that the same result is obtained with the 21 days of simulation (data not shown). This confirms the permanent character of this drift. When this averaged component is subtracted from the modeled currents, the obtained simulated currents have the same characteristics than those observed in situ and correspond to an inertial oscillation.

The inertial motions are clockwise with speeds up to $0.4 \mathrm{~m} \mathrm{~s}^{-1}$ near the surface. They extend throughout the water column with the lower layer oscillating in opposite phase with the layer above the thermocline. The simulated inertial components are of the same order as the geostrophic NC. Hence the geostrophic current is weakened, at each inertial period, when the inertial oscillation is in the opposite direction (as on June 14, 09h00 at 24 m; Fig. 8c). On the contrary, half a period after, the geostrophic current is reinforced when the inertial current is in the same direction.

These inertial components, which overlap the average currents, are generated by the rough variations of the wind, which often occur in the region. Here, this oscillation probably originates from the wind burst on June 10 (Figs. 11 and 12). The simulated inertial motion is maintained, maybe excessively, by a weak friction term, and is permanently present throughout the simulation. According to the occurrence of wind bursts or stops, the inertial motion can be amplified (e.g. June 13, 12h00), modified and disorientated (e.g. June 14, 00h00), or weakened (e.g. June 15, 00h00). 


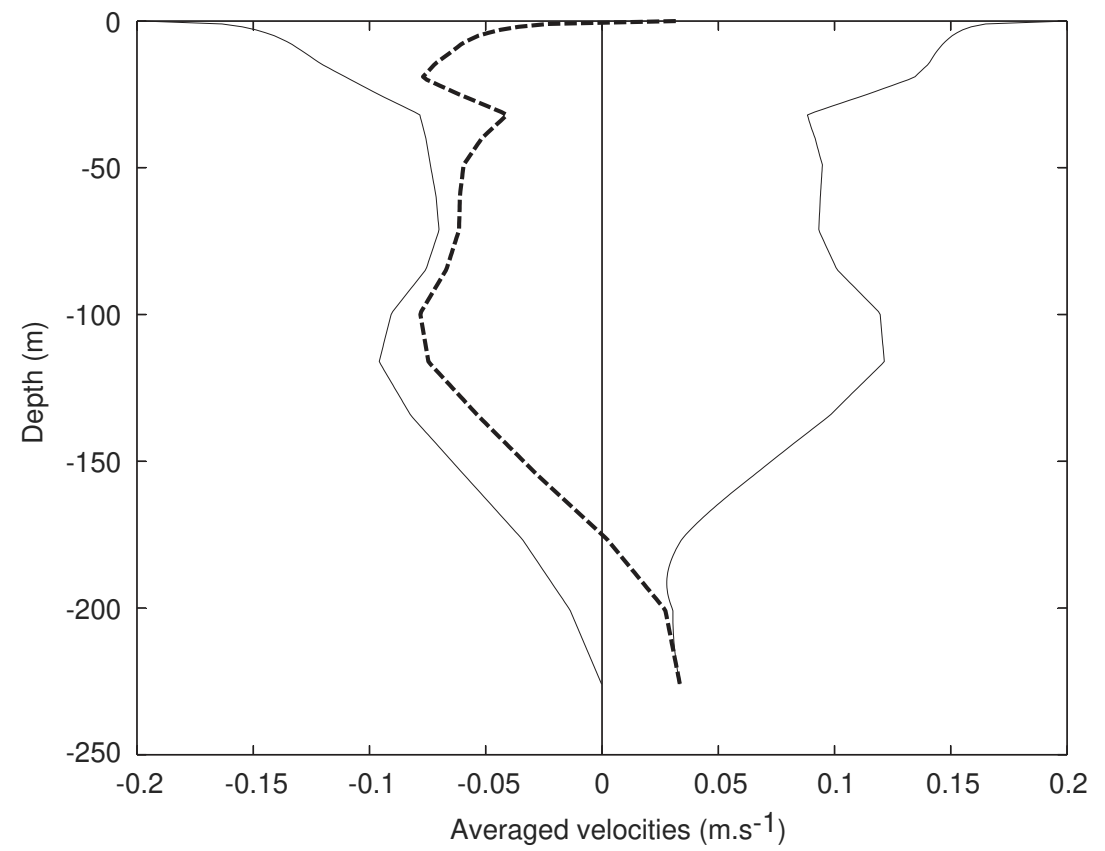

Fig. 11. Amplitude (solid positive line), eastward (dotted line) and northward (solid line) velocities ( $\mathrm{m} \mathrm{s}^{-1}$ ) simulated at point $\mathrm{O}$ (latitude $42.5^{\circ} \mathrm{N}$, longitude $3.5^{\circ} \mathrm{E}$ ) averaged between June 9, $00 \mathrm{~h} 00$ and June 15, $18 \mathrm{~h} 00$.

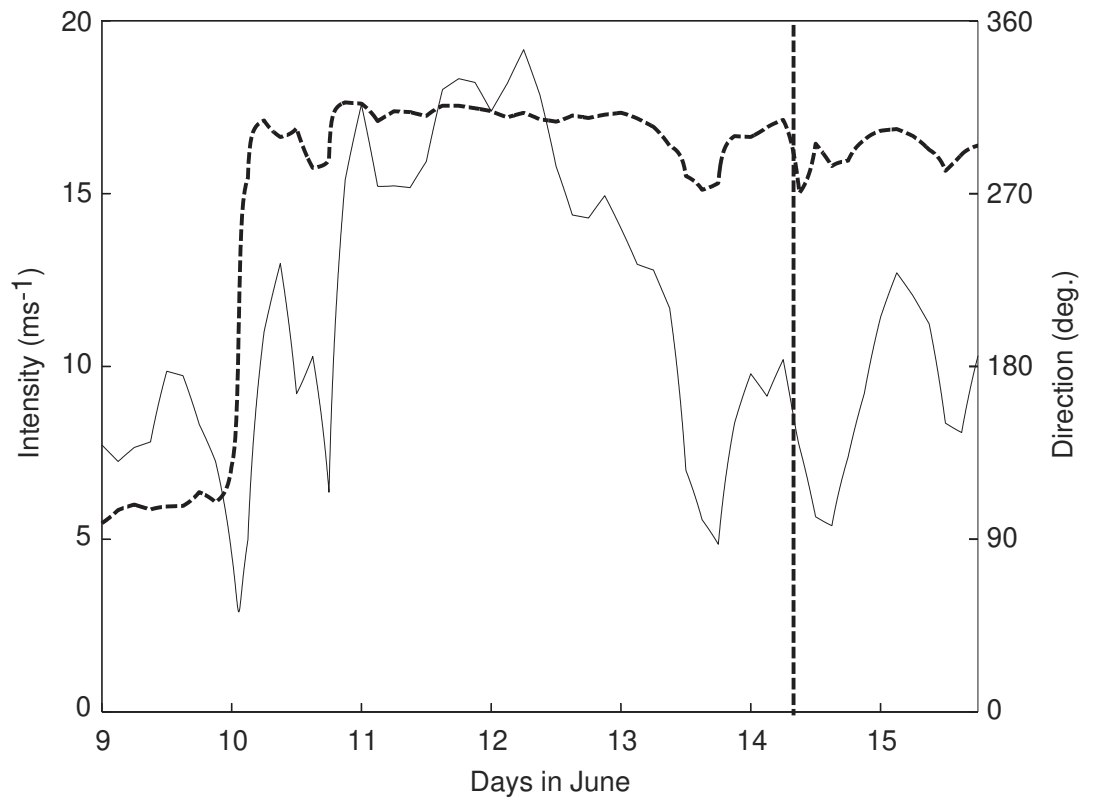

Fig. 12. Wind stress intensity (solid line) and direction (dotted line) between June 9, 00h00 and June 15, $18 \mathrm{~h} 00$ at point O. 
This analysis shows the presence of a strong inertial oscillation on transect 4 . Its signature is very clear in the ADCP measured currents because the NC is more south and, hence, not present on the transect. It is also present in the model results, but slightly hidden by the presence of the modeled NC. This inertial oscillation probably originates from the strong tramontane event having started on June 10, four days before the cruise.

\section{Discussion}

\subsection{Sensitivity tests}

Representation of the $\mathrm{NC}$ in our simulations raises questions about the open boundary. Various methods have already been proposed to simulate circulation systems with spatial extension larger than the coastal numerical domain.

One method is to start the model at rest and wait for the adjustment of the inner solution in response to an external forcing applied at open boundaries (Echevin et al., 2000; Pinazo et al., 1996). But it may require a long spin-up period and may be seen as a rather uncertain way to control the resulting equilibrated geostrophic circulation (if the adjustment process ever succeeds).

A second method consists in using interpolated dynamical fields provided by an Ocean General Circulation Model (OGCM) of the Mediterranean Sea (Auclair et al., 2001; Beckers et al., 1997). This is obviously a way to deal with realistic forcings. However, in some cases, the so-called nested grid technique may lead to unrealistic transitional solutions, especially when strong unconsistencies between bottom interpolated currents and local coastal bathymetry gradient occur. Auclair et al. (2000b) showed that the spin-up produced by simplistic nested-grid methods can be avoided if the OGCM outputs are interpolated under some dynamical stability constraints which can be calculated from the linear discrete equations of the coastal model itself.

Neither of these methods was used here; but a third one, which uses the linear method proposed by Estournel et al. (2003). The aim of this method is to initialize the coastal model and to force its open boundary with adjusted geostrophic currents. The forcing current is calculated thanks to a simple linear model (see appendix) associated to some appropriate input hypotheses, such as the upstream and downstream positions of the NC, its vertical shear and reference vertical profiles for both temperature and salinity. The advantage of this method is to provide a powerful tool to study the sensitivity of the model to the upstream condition. Indeed, Auclair et al. (2003) showed that the possible intrusion of the $\mathrm{NC}$ on the continental shelf depends partly on the thickness of the current. And the latter is easily set by the parameterization proposed by Estournel et al. (2003) for the vertical shear of the geostrophic current (see Eqs. (2) and (3) in the appendix). Nonetheless, a drawback of this method is that it clearly does not allow to reproduce the full complexity of the three dimensional circulation (that a nested grid strategy based on OGCM outputs could provide). Indeed, some difficulties prevented us from obtaining a better fit of the NC characteristics than the one presented in Section 3.3.

One of the difficulties is to simulate a thermocline, from 15-20 to 40-50 m, which coexists with a strong but deeper current. Indeed the $\mathrm{NC}$ has a vertical extension which is deeper than $150 \mathrm{~m}$; and its instability induces turbulence able to homogenize the whole water column. If the initial model current is too strong, it can break the thermocline. If it is too weak, after several hours of simulation, it appears only above the thermocline and loses its vertical extent. In fact, there is an important nonlinear sensitivity of the model outputs to the vertical shear of the current, $R(z)$, and the strength of the forcing current at the open boundaries, $R^{*}$. The successive hand-made trials and errors will be automated in the future with an optimal control method (Leredde et al., 2002; Leredde et al., 1999).

Another important factor on which we did not do sensitivity analysis is the model bathymetry. Indeed the model bathymetry is smoother than the real bathymetry for two main reasons. First, a $3 \mathrm{~km}$ grid mesh does not allow to reproduce the spatial variability of the continental slope with its 
numerous and sharp canyons. Second, a way to deal with the well known truncation error problem, inherent to the use of a sigma co-ordinate system over steep topography (Haney, 1991), is to limit the slope of the sigma surfaces. Our generalized vertical co-ordinate system can be used to control the slope of the vertical levels (Auclair et al., 2000a; Pietrzak et al., 2002) especially in the upper part of the water column where the truncation error can be significantly reduced. However this method is less efficient near the bottom because vertical levels are more constrained by the seafloor. This means that the slope of the lowest levels is not likely to be reduced unless the slope of the topography is reduced itself. This can be easily achieved with additional smoothing applied to the model topography. In our case, the slope of the model bathymetry is bounded by a threshold criterion proposed by Beckman and Haidvogel (1993).

The main branch of the $\mathrm{NC}$ follows the continental slope, both in the in situ measurements and in the simulation results. But the real NC is narrower than the simulated one (Fig. 7a). This is interpreted as due to the fact that the continental slope is steeper in reality than in the model. Moreover, the observed and modeled NC vary slightly in position and direction. Whereas the $\mathrm{NC}$ is observed a little more to the north $\left(0.1^{\circ}\right.$ of latitude) than the modeled $\mathrm{NC}$ on transect 13, it is observed everywhere else more to the south. Also, on transects 8, 11 and 12, the observed NC goes south-westward, whereas its direction is westward in the model. Modeling simulations with higher resolution bathymetry would confirm whether these differences could be due to that factor.

The bathymetry probably also plays a crucial role in the fluctuations of the $\mathrm{NC}$, and notably its meanders. The model shows three main and steady meanders of the NC along the GoL shelf break. As the cruise was not dedicated to the NC observation, the real number of meanders of the $\mathrm{NC}$ cannot be determined from the in situ data. The smooth model bathymetry could also have an impact on the intrusions of the NC over the shelf, as discussed below.

\subsection{Origin of the intrusions on the shelf}

During the SARHYGOL 3 cruise, intrusions of the $\mathrm{NC}$ were observed both at the eastern end and at the center of the gulf.

Intrusions of the NC in the eastern part of the Gulf of Lions have previously been mentioned in the literature. They were generally observed to take place after a strong mistral period (Millot and Wald, 1980) or during weak north-eastern winds (Petrenko, 2003). Modeling the NC by a baroclinic coastal jet, which follows a vertical wall interrupted by a gulf, shows some cases of intrusions of the jet (or part of the jet) in the gulf. These intrusions depend on the depth of the jet versus the depth of the gulf and/or its stratification (Echevin et al., 2003). These intrusions could also depend on the water "budget" of the gulf; a deficit of water mass in the gulf could favour the intrusions of the NC (Estournel et al., 2003). In the case of the SARHYGOL 3 cruise, the intrusion at the eastern side of the gulf occurs during weak north-eastern winds and after a strong event of north wind (mistral) that ended on June 9. But the present state of analysis cannot prove whether the intrusion is correlated to the mistral event. Indeed, during the 21 days of simulation, no correlation was found between eastern intrusions and periods of strong mistral (J. Gatti, personal communication). Further tests need to be done to check the importance of wind forcing and stratification on the occurrence of eastern intrusions. These tests could not be done here due to the Sarhygol cruise strategy, and hence scarcity of available data on stratification.

It makes no doubt that bathymetry also influences this separation between the $\mathrm{NC}$ main branch and its intrusion. In the model, the zone of the $\mathrm{NC}$ separation corresponds to the beginning of the continental shelf extension. In reality, the bathymetry is less smooth than the modeled one (from east to west, several canyons are present: the Toulon, the La Ciotat, and the Cassidaigne canyons). The location of the separation, as predicted by the model, may not correspond to the exact location in reality. Future cruises should take place in order to try to locate directly this zone in situ. Then moorings should be located at 
the found locations to check whether the intrusions systematically occur at about the same place. As far as water budget, at the time of the cruise, it had not rained for a while and the Rhone River input was low (as expected for the season), so it could indeed favor intrusions.

Intrusions of the $\mathrm{NC}$ on the shelf can also occur at other locations along the continental slope (Petrenko, 2003). In our study, an intrusion of the $\mathrm{NC}$ also occurs at the centre of the continental shelf. Intrusions in the middle of the shelf are explained by modeling as due to the water pumping created by a cyclonic circulation on the western side of the gulf and an anticyclonic circulation on the eastern side (Estournel et al., 2003). Estournel et al. found that these rotating circulations are wind-driven, the former by the tramontane, and the latter by the mistral.

The eastern intrusion lasts about 5 days, and is generally around $0.4-0.5 \mathrm{~Sv}$. The northward intrusion, at the center of the GoL, is detected during less than $12 \mathrm{~h}$, and is around $0.1-0.15 \mathrm{~Sv}$. The flux of the latter is about four times less than the flux of the former. The eastern intrusion will obviously have a much more important influence on the shelf dynamics than the central intrusion.

\subsection{Vertical structure of the inertial oscillations}

Inertial oscillations can be generated, among other reasons, by local wind changes, as early demonstrated by Pollard (1970). Millot and Crépon (1981) observed strong inertial oscillations in the Gulf of Lions. They showed that the inertial currents had a 2-layer baroclinic structure, with a $\sim 180^{\circ}$ phase shift between the upper and the lower layer. Similar inertial oscillations were also observed in this gulf in June 1998, after strong wind variations with a still well-stratified water column (Petrenko, 2003). Petrenko observed that, in the surface layer, the speed of the inertial oscillation was locally as high as $200 \%$ the NC speed $(0.2$ versus $0.1 \mathrm{~m} \mathrm{~s}^{-1}$ ). Otherwise, when integrated over their own depth, the inertial current was about $\frac{2}{3}$ the NC. In the present study, the characteristics of the inertial oscillations, described in Section 3.4, correspond to the commonly observed inertial oscillations. In situ, the oscillation is striking along transect 4 (maximum of $0.6 \mathrm{~m} \mathrm{~s}^{-1}$ ) since it takes place with nearly no geostrophic current present. In the model, the NC being more north than in situ in that zone of the gulf, the inertial oscillation is damped by the current presence. An important advantage of the model is that it shows which wind event has generated or, at least, strongly reinforced the inertial oscillation.

The only surprise of the modeled outputs comes from the motion displayed in the bottom layer (Fig. 10). At the beginning of each inertial period, the current is, at first, stronger around $150 \mathrm{~m}$ than at the top of the layer, localized around $60 \mathrm{~m}$. During the inertial cycle, a propagation seems to occur from the bottom up towards the surface. This visual "impression" can be explained by the baroclinic structure of the geostrophic current. Indeed the $\mathrm{NC}$ is almost null around $150 \mathrm{~m}$ and increases from $100 \mathrm{~m}$ up to $60 \mathrm{~m}$. At $150 \mathrm{~m}$, as the inertial motion is not in opposition with the geostrophic current, it can easily increase. At $60 \mathrm{~m}$, when the inertial motion is in opposition with the geostrophic current, the resulting current is almost null. Later in the inertial cycle, since the inertial current continues to turn, it overtakes the geostrophic current, even at $60 \mathrm{~m}$; the resulting current then appears to be stronger.

\section{Conclusions and perspectives}

The shelf circulation of the Gulf of Lions is complex due to the combined effects of various forcings (winds, NC, Rhone plume, topography, etc.). These characteristics can be met in many other coastal zones; hence the study of this zone is of general interest for coastal studies.

The SARHYGOL cruises (10 cruises of $48 \mathrm{~h}$ during 2000-2001) were performed in order to obtain quasi-synoptic views of the circulation. But, as shown in this study of the third SARHYGOL cruise, it is not obvious, only with the ADCP data acquired in situ, to determine the generating process of the observed inertial oscillations or to explain other hydrodynamic features detailed above. Indeed the current data, while acquired throughout the gulf as quickly as possible, are still not strictly synoptic. Several forcing mechanisms 
act together. Certain hydrodynamic features may only be transitional while others may last longer. Hence modeling is the perfect tool to test hypotheses or make sensitivity studies in order to obtain a better understanding of the observed phenomena.

For this study, this combined in situ and modeling analysis has allowed us to establish the following results:

- The eastern intrusion of the $\mathrm{NC}$ over the shelf lasted during 5 days and occurred after a north wind event. The split between the main branch of the NC and the eastern intrusion is probably located at the beginning of the continental shelf.

- A northward current, measured in the center of the shelf, was due to a transitional intrusion of the NC over the shelf, generated by the simultaneous presence of a cyclonic and anticyclonic circulation, respectively west and east of the gulf.

- An inertial oscillation, with maximum surface current of $0.6 \mathrm{~m} \mathrm{~s}^{-1}$, was clearly measured in the western side of the gulf. Its signature is strong because no geostrophic current is present. This inertial oscillation probably originates from the strong tramontane event having started 4 days before.

Differences between the observed circulation and the modeled one prove that the path of the $\mathrm{NC}$ depends on the gulf vertical stratification; a shallow thermocline on the gulf keeps the $\mathrm{NC}$ offshore. Hence the modeled $\mathrm{NC}$ is more south than the observed NC in the eastern part of the gulf where the stratification of the shelf is shallower in the model than in situ (vice versa in the western part of the gulf). The position of the modeled NC also depends strongly on the initial state and on the boundary conditions chosen for the simulation. These will be improved in the future by using operational systems (such as Mercator, or MFSTEP) and data assimilation. The model bathymetry probably also plays an important role so its refinement could bring further understanding of the complex coastal circulation of the GoLs.
This study also shows that quasi-synoptic current maps have their limitations and need to be complemented by time series acquired at moorings. The authors plan to do as such in the following years by implementing ADCP moorings at crucial locations (GOLTS: GoL Time Series project, started in 2002).

\section{Acknowledgements}

The cruises and study were financed by the PNEC and PATOM, French programs of the INSU. Rhone data were nicely provided by the "Compagnie Nationale du Rhône". We are grateful to the crews of the Téthys II, Gilles Rougier and Sylvain Ouillon for their help. We thank the PNEC colleagues and the students who have participated to the SARHYGOL cruises.

\section{Appendix A}

First, the expression of the pressure gradient, $\nabla p$, is simplified by separating its vertical and horizontal dependences:

$-\frac{\nabla p}{\rho_{0}}=-\frac{R(z) \nabla p_{S}}{\rho_{0}}$,

where $\nabla p_{S}$ is the surface pressure gradient and $R(z)$ can be considered as a dimensionless representation of the vertical shear of the geostrophic current. Similarly the horizontal components of the current are given by

$(u, v)=\frac{R(z)}{\bar{R}}(U, V)$,

where $(U, V)$ are the components of the transport and $\bar{R}$ is the following bottom depth dependent variable:

$\bar{R}=\int_{-h}^{0} R\left(z^{\prime}\right) \mathrm{d} z^{\prime}$

with $h$ the bathymetry.

$R(z)$ features a dimensionless vertical section of the NC in summer and is more specifically chosen for the SARHYGOL 3 cruise period (Fig. 6). 
Neglecting advective and time variation terms, a set of equations for the components of the transport can be obtained from Eqs. (1)-(3):

$-f V=-\frac{\bar{R}}{\rho_{0}} \frac{\partial p_{S}}{\partial x}-r \frac{R_{b}}{\bar{R}} U+\vartheta(U)$,

$f U=-\frac{\bar{R}}{\rho_{0}} \frac{\partial p_{S}}{\partial y}-r \frac{R_{b}}{\bar{R}} V+\vartheta(V)$,

where $R_{b}=R(z)$ at $z=-h$. The second term on the right hand side of (4) and (5) is a linear expression for the bottom friction given by the product of a constant, $r=0.0013 \mathrm{~s}^{-1}$, with the bottom current estimated from (2). Finally $\vartheta$ is a horizontal viscosity operator given by

$\vartheta()=.v\left(\frac{\partial}{\partial x} h \frac{\partial}{\partial x}\left(\frac{\dot{h}}{h}\right)\right)+v\left(\frac{\partial}{\partial y} h \frac{\partial}{\partial y}\left(\frac{\dot{h}}{h}\right)\right)$

with $v=15 \mathrm{~m}^{2} \mathrm{~s}^{-2}$.

At this stage the rigid lid approximation can be used in order to express the transport in terms of the barotropic stream function $\psi: U=-\partial \psi / \partial y$ and $V=\partial \psi / \partial x$. The surface pressure term can also be dropped if the following operators $\partial / \partial y\left(\frac{\dot{\bar{R}}}{)}\right.$ and $-\partial / \partial x\left(\frac{\dot{\bar{R}}}{)}\right)$ are, respectively, applied to (4) and (5) and the resulting equations summed up. We then obtain an equation for $\psi$ given by

$$
\begin{aligned}
- & \frac{\partial}{\partial y}\left(\frac{f}{\bar{R}}\right) \frac{\partial \psi}{\partial x}+\frac{\partial}{\partial x}\left(\frac{f}{\bar{R}}\right) \frac{\partial \psi}{\partial y} \\
= & r \frac{\partial}{\partial x}\left(\frac{R_{b}}{\bar{R}^{2}} \frac{\partial \psi}{\partial x}\right)+r \frac{\partial}{\partial y}\left(\frac{R_{b}}{\bar{R}^{2}} \frac{\partial \psi}{\partial y}\right) \\
& -\frac{\partial}{\partial x}\left(\frac{\vartheta(\partial \psi / \partial x)}{\bar{R}}\right)-\frac{\partial}{\partial y}\left(\frac{\vartheta(\partial \psi / \partial y)}{\bar{R}}\right) .
\end{aligned}
$$

Discretization of (7) on the model grid leads to a system of linear equations. Then boundary conditions have to be specified in order to compute a solution. The open boundaries are set to the summer mean characteristics of the $\mathrm{NC}$ reported by numerous authors (Petrenko, 2003; and included literature): practically a $30 \mathrm{~km}$ wide current, flowing westward along the continental slope. The input flux, $R^{*}$, is given by the difference of maximal and minimal values of the stream function taken on the eastern boundary of the domain.
The thickness of the current depends on our choice for the mean vertical section $R(z)$. Fig. 6 shows that the later is maximum at the surface and vanishes when $z<-250 \mathrm{~m}$. A consequence is that the $h$ dependent function $\bar{R}$ is constant when $h>250 \mathrm{~m}$. Therefore (as long as the $f$ plan approximation is made), the left hand side terms of (7) vanish for all $\psi$ when $h>250 \mathrm{~m}$, as well as the bottom friction terms (since $R_{b}=0$ ). This proves the lack of topographic effects on the current in deep areas. On the other hand, in shallow areas $(h<250 \mathrm{~m})$, the left hand side terms of (7) indicate that the isolines of $\psi$ and $f / \bar{R}$ will tend to be parallel (which is equivalent to the current tending to flow along isobaths). Nonetheless, small cross-slope currents can be expected because of the bottom friction and horizontal viscosity terms on the right hand side of (7).

An initial state for all the model variables can now be computed from a stream function field satisfying (7) and our prescribed boundary conditions. Components of transport are directly deduced from $\psi$. Horizontal components of the current are given by (2). Then surface pressure is calculated from (4) and (5). Horizontal perturbations of the density field are calculated using (1) and the hydrostatic assumption. Total density field is then obtained by adding a $z$ dependent reference state chosen to feature a mean seasonal vertical section of density for the GoLs. Temperature and salinity are finally deduced from density, thanks to the equation of state of the model and to an additional equation constrained by the ratio of temperature and salinity variances.

Note that, in order to improve the stability of the initial state, most of the numerical schemes used to compute Eqs. (1)-(7) are identical to those used in the model.

\section{References}

Auclair, F., Casitas, S., Marsaleix, P., 2000a. Application of an inverse method to coastal modelling. Journal of Atmospheric and Oceanic Technology 17, 1368-1391.

Auclair, F., Marsaleix, P., Estournel, C., 2000b. Sigma coordinate pressure gradient errors: evaluation and reduction by an inverse method. Journal of Atmospheric and Oceanic Technology 17, 1348-1367. 
Auclair, F., Marsaleix, P., Estournel, C., 2001. The penetration of the Northern Current over the Gulf of Lions (Mediterranean) as a downscaling problem. Oceanologica Acta 24, 529-544.

Auclair, F., Marsaleix, P., De Mey, P., 2003. Space-time structure and dynamics of the forecast error in a coastal circulation model of the Gulf of Lions. Dynamics of Atmospheres and Oceans 36, 309-346.

Beckers, J.-M., Brasseur, P., Nihoul, J.C.J., 1997. Circulation of the western Mediterranean: from global to regional scales. Deep Sea Research 44 (3-4), 531-549.

Beckman, A., Haidvogel, D., 1993. Numerical simulation of flow around a tall isolated seamount. Journal of Physical Oceanography 23, 1736-1753.

Castellon, A., Salat, J., Maso, M., 1985. Some observations on Rhone fresh water plume in the Catalan coast. In: CIES (Ed.), Rapp. Comm. int. Mer Medit. Monaco, pp. 119-121.

Chereskin, T.K., Levine, M.D., Harding, A.J., Regier, L.A., 1989. Observations of near-inertial waves in acoustic doppler current profiler measurements made in the mixed layer dynamics experiment. Journal of Geophysical Research 94 (C6), 8135-8145.

Conan, P., Millot, C., 1995. Variability of the northern current off Marseilles, western Mediterranean Sea, from February to June 1992. Oceanologica Acta 18 (2), 193-205.

Delleville, S., 1997. Contribution à la modélisation de la dynamique marine d'été du golfe du Lion. Application d'un modèle emboité passif., Université d'Aix-Marseille II.

Demarq, H., Wald, L., 1984. La dynamique superficielle du panache du Rhône d'après l'imagerie infrarouge satellitaire. Oceanologica Acta 7 (2), 159-162.

Dufau-Julliand, C., Marsaleix, P., Petrenko, A., Dekeyser, I. Three-dimensional modeling of the Gulf of Lion's hydrodynamics (northwest Mediterranean) during January 1999 (MOOGLI3 Experiment) and late winter 1999: Western Mediterranean Intermediate Water's (WIW's) formation and its cascading over the shelf break. Journal of Geophysical Research, in press.

Durrieu de Madron, X., Radakovitch, O., Heussner, S., Loye-Pilot, M.D., Monaco, A., 1999. Role of the climatological and current variability on shelf-slope exchanges of particulate matter: evidence from the Rhône continental margin (NW Mediterranean). Deep-Sea Research 46, 1513-1538.

Echevin, V., De Mey, P., Evensen, G., 2000. Horizontal and vertical structure of the representer functions for sea surface measurements in a coastal circulation model. Journal of Physical Oceanography 30 (10), 2627-2635.

Echevin, V., Crépon, M., Mortier, L., 2003. Interaction of a coastal current with a gulf: application to the shelf circulation of the Gulf of Lions in the Mediterranean Sea. Journal of Physical Oceanography 33, 188-206.

Estournel, C., Kondrachoff, V., Marsaleix, P., Vehil, R., 1997. The plume of the Rhone: numerical simulation and remote sensing. Continental Shelf Research 17 (8), 899-924.

Estournel, C., Broche, P., Marsaleix, P., Devenon, J.L., Auclair, F., Vehil, R., 2001. The Rhone river plume under unsteady conditions: numerical and experimental results. Estuarine, Coastal and Shelf Sciences 53, 25-38.

Estournel, C., Durrieu de Madron, X., Marsaleix, P., Auclair, F., Julliand, C., Vehil, R., 2003. Observation and modelisation of the winter coastal oceanic circulation in the Gulf of Lions under wind conditions influenced by the continental orography (FETCH experiment). Journal of Geophysical Research 108 (C3), 8059.

Flexas, M., Durrieu de Madron, X., Garcia, M.A., Canals, M., Arnau, P., 2002. Flow variability in the Gulf of Lions during the MATER HFF experiment (March-May 1997). Journal of Marine Systems 33-34, 197-214.

Gaspar, P., Gregoris, Y., Lefevre, J.M., 1990. A simple eddy kinetic energy model for simulations of the oceanic vertical mixing tests at station Papa and long-term upper ocean study site. Journal of Geophysical Research 95, 179-193.

Haney, R.L., 1991. On the pressure gradient force over steep topography in sigma coordinate ocean models. Journal of Physical Oceanography 21, 610-619.

Lapouyade, A., Durrieu de Madron, X., 2001. Seasonal variability of the advective transport of particulate matter and associated organic carbon in the Gulf of Lions (NW Mediterranean). Oceanologica Acta 24, 295-312.

Leredde, Y., Devenon, J.L., Dekeyser, I., 1999. Turbulent viscosity optimized by data assimilation. Annales Geophysicae 17, 1463-1477.

Leredde, Y., Dekeyser, I., Devenon, J.L., 2002. T-S data assimilation to optimise turbulent viscosity. An application to the Berre lagoon hydrodynamics. Journal of Coastal Research 18 (3), 555-567.

Marsaleix, P., Estournel, C., Kondrachoff, V., Vehil, R., 1998. A numerical study of the formation of the Rhône River plume. Journal of Marine Systems 14 (1-2), 99-115.

Millot, C., 1982. Analysis of upwelling in the Gulf of Lions. In: Nihoul, J.C.J. (Ed.), Hydrodynamics of Semi-enclosed Seas,. Elsevier, Amsterdam, pp. 143-154.

Millot, C., 1990. The Gulf of Lion's hydrodynamics. Continental Shelf Research 10 (9-11), 885-894.

Millot, C., 1991. Mesoscale and seasonal variabilities of the circulation in the Western Mediterranean. Dynamics of Atmosphere and Oceans 15, 179-214.

Millot, C., 1999. Circulation in the Western Mediterranean Sea. Journal of Marine Systems 20, 423-442.

Millot, C., Crépon, M., 1981. Inertial oscillations on the Continental Shelf of the Gulf of Lions-observations and theory. Journal of Physical Oceanography 11 (5), 639-657.

Millot, C., Wald, L., 1980. The effects of Mistral wind on the Ligurian current near Provence. Oceanologica Acta 3 (4), 399-402.

Monaco, A., Courp, T., Heussner, S., Carbonne, J., Fowler, S.W., Deniaux, B., 1990. Seasonality and composition of particulate fluxes during ECOMARGE-I, western Gulf of Lions. Continental Shelf Research 10 (9-11), 959-987.

Moutin, T., Raimbault, P., Golterman, H.L., Coste, B., 1998. The input of nutrients by the Rhône river into the 
Mediterranean Sea: recent observations and comparison with earlier data. Hydrobiologia 373,374, 237-246.

Naudin, J.J., Cauwet, G., Fajon, C., Oriol, L., Terzic, S., Devenon, J.L., Broche, P., 2001. Effect of mixing on microbial communities in the Rhone River Plume. Journal of Marine System 28, 203-227.

Petrenko, A.A., 2003. Circulation features in the Gulf of Lions, NW Mediterranean Sea; importance of inertial currents. Oceanologica Acta 26, 323-338.

Pietrzak, J., Jakobson, J.B., Burchard, H., Vested, H.J., Petersen, O., 2002. A three-dimensional hydrostatic model for ocean modelling using a generalised topography following co-ordinate system. Ocean Modelling 4, 173-205.
Pinazo, C., Marsaleix, P., Millet, B., Estournel, C., Véhil, R., 1996. Spatial and temporal variability of phytoplankton biomass in upwelling areas of the northwestern Mediterranean: a coupled physical and biogeochemical modelling approach. Journal of Marine Systems 7 (2-4), 161-191.

Pollard, R.T., 1970. On the generation by wind of inertial waves in the ocean. Deep-sea Research 17, 161-191.

Raimbault, P., Durrieu de Madron, X., 2003. Research activities in the GoL (NW Mediterranean) within the 1997-2001 PNEC project. Oceanologica Acta 26, 291-298.

Reffray, G., Fraunié, P., Marsaleix, P., 2004. Secondary flows induced by wind forcing in the Rhône region of freshwater influence. Ocean Dynamics 54, 179-196. 